\title{
Are patients with inflammatory eye disease treated with systemic immunosuppressive therapy at increased risk of malignancy?
}

\author{
William B Yates ${ }^{1,2,4}$, Peter J McCluskey ${ }^{2,3}$ and Denis Wakefield ${ }^{1,2,5^{*}}$
}

\begin{abstract}
The purpose of this study is to review the literature on the risk of malignancy in patients with inflammatory eye disease (IED) treated with systemic immunosuppressive (IS) therapy. Relevant databases in transplant medicine, autoimmune diseases and literature regarding uveitis and scleritis were reviewed. Literature with regards systemic IS therapy in transplant recipients and patients with autoimmune diseases revealed a significant increase in malignancies, especially non-melanocytic skin cancers and lymphomas. Studies of patients with IED were limited in number and scope, with no studies adequately evaluating the incidence of malignancy in these patients. Difficulties associated with the evaluation of the risk of malignancy associated with IS therapy in patients with IED include the heterogeneity of the disease and treatment regimens as well as the low frequency of IED, its variable severity and the lack of adequate long-term follow-up studies. Systemic IS therapy is an important therapeutic option in the treatment of patients with severe IED. A well-designed, comprehensive, multi-centre long-term follow-up study is required to evaluate the risk of malignancy in patients with specific IED diseases treated with defined systemic IS therapy. Until such evidence is available, we recommend the adoption of preventative strategies to help minimise the risk of malignancy in such patients.
\end{abstract}

Keywords: Immunosuppressive therapy, Incidence, Inflammatory eye disease, Malignancy, Neoplasia

\section{Review}

\section{Introduction}

The aims of therapy in patients with inflammatory eye disease (IED) are to control ocular inflammation, limit the progression of disease, preserve vision, maintain the quality of life and prevent local and systemic side effects. The treatment of severe IED with immunosuppressive (IS) therapy is a dilemma for the physician in determining whether the benefits of such therapy outweigh the risk of inducing other diseases, such as infection and malignancy. Literature regarding the use of IS therapy in the treatment of patients with autoimmune diseases indicates that these drugs induce secondary or de novo malignancies [1-3]. A crucial clinical question is if the manipulation of the immune system in patients with

\footnotetext{
* Correspondence: d.wakefield@unsw.edu.au

${ }^{1}$ Inflammation Research Unit, School of Medical Sciences, University of New South Wales, Sydney, NSW 2052, Australia

2Department of Ophthalmology, St Vincent's Hospital, Sydney, NSW 2052, Australia

Full list of author information is available at the end of the article
}

autoimmune diseases and transplant patients results in an increase in skin and other malignancies, does this mean that patients with IED treated with similar longterm IS therapy are also at such risk? Studies examining the risk of malignancies in transplant recipients, patients with human immunodeficiency virus (HIV) and autoimmune diseases show that suppressing the immune system predisposes the patients to carcinogenesis $[4,5]$.

The importance of tumour immunosurveillance in humans has been inferred from clinical observations. The majority of evidence concerning the effects of IS therapy on the host immune response and tumour development is derived from studies of transplant recipients. The effectiveness of IS therapy in improving the outcome of organ transplantation has resulted in the development of malignancies and cardiovascular disease emerging as the major causes of patient mortality, rather than graft rejection as previously observed $[1,3,6]$. Solid organ transplant recipients given systemic immunosuppressive therapy require lifelong therapy. In contrast, patients with systemic 
inflammatory diseases are frequently treated with a number of immunosuppressive drugs, often concurrently and over a shorter time course, but nonetheless may still be predisposed to increased tumour risk [7].

Patients with severe IED are often treated with systemic immunosuppressive therapy. These patients either do not respond to topical or local therapies, have a type of IED not controlled by systemic corticosteroids or require aggressive therapy to prevent progressive vision loss [8]. The treatment of patients with chronic IED typically encompasses the use of corticosteroids with additional agents. This is primarily due to the significant side effects associated with long-term steroid therapy, and hence agents such as methotrexate (MTX), azathioprine (AZA), cyclosporine (CSA), mycophenolate mofetil (MMF) and, occasionally, alkylating agents (cyclophosphamide and chlorambucil) are given concurrently as steroid-sparing medications. Similarly, the efficacy of IS therapy in the treatment of a number of diseases such as ocular cicatricial pemphigoid [9], Behçet's disease [10] and Wegener granulomatosis [11] has been well documented.

Patients with idiopathic IED do not have an underlying systemic disease. Thus, these patients are a suitable group to examine the effect of immunosuppression and malignancy development in otherwise healthy individuals.

This review examines the evidence regarding the risk of malignancies in patients treated with systemic immunosuppressive therapy. The focus of the review is the evaluation of the evidence in the settings of transplant recipient, patients with autoimmune disease and IED. The aims are to evaluate the available literature and provide recommendations for further studies and prevention strategies to address this important clinical question.

\section{Materials and methods}

A search of articles using the MEDLINE database and PubMed (National Library of Medicine) was performed to identify all relevant articles published in the area. Terms and phrases used for the search included immunosuppression, malignancy, transplantation, rheumatoid disease, autoimmune, uveitis, scleritis and ocular cicatricial pemphigoid. Articles were included if they were in English language and if full copies of the articles could be obtained. Articles were only included if they were from peer-reviewed journals. Articles were examined in reference to levels of evidence and recommendations set by the National Health and Medical Research Council. Articles were stratified on evidence strength dependent on study design, which included systematic reviews, randomised controlled trials (RCTs) and cohort study data. Review articles and editorials were also analysed and included if evidence was suitable for inclusion.

\section{Results}

The incidence of malignancy in patients treated with IS therapy differed depending on the specific IS agents and the indication for therapy. Table 1 illustrates the incidence of malignancy in solid transplant recipients treated with a number of immunosuppressive agents. Table 2 highlights the literature relevant to systemic autoimmune diseases, and Table 3 summarises the literature regarding systemic immunosuppressive therapy in patients with IED.

\section{Transplant recipients}

Evidence from observational studies of transplant recipients provides significant evidence for the increased risk of malignancy associated with IS therapy. The emergence of effective systemic IS therapy for allograft recipients has seen a reduction in immunologic and non-immunologic graft rejection. However, the major contributor to mortality following solid organ transplantation is not graft rejection but malignancies and cardiovascular disease associated with IS therapy [1,34].

The Cincinnati Transplant Tumour Registry provided a great deal of evidence with regards to the effects of systemic IS therapy during the era (1980s and 1990s) when AZA and CSP were the major drugs used in post-transplantation patients. During 1988, it reported on 3,351 de novo malignancies in 3,320 patients treated with systemic IS therapy. Of this group, 3,139 were treated with AZA, and the majority of malignancies observed were skin $(n=1,255)(40 \%)$. Results of patients treated with CSP highlighted that the greatest proportion of the 412 tumours were lymphomas $(n=119)$ and skin cancers $(n=90)(29 \%$ and $22 \%$, respectively) $[34,35]$.

Skin malignancies, especially non-melanocytic skin cancer (NMSC), are the most common post-transplant tumours. Heart and renal transplant recipients are at an increased risk of squamous cell carcinoma (SCC) and basal cell carcinoma (BCC) with some studies quantifying the risk as 250 and 65 times higher than the general population, respectively $[2,36]$. Two theories have been proposed to explain this association including (1) solarinduced mutations coupled with immunosuppression reduces tumour surveillance [37] and (2) metabolites from certain IS agents such as AZA appear phototoxic and thus increase the skin's sensitivity to ultraviolet light damage [38]. Previous studies indicate that although solar radiation may be a major contributor of skin carcinogenesis, one increasingly important risk factor is the host's immune status $[6,39,40]$. To further illustrate this observation, one particular study analysed the distribution of NMSC in sites not exposed to solar radiation and 
Table 1 Studies which demonstrated an increased incidence of malignancy associated with systemic immunosuppressive therapy in transplant recipients

\begin{tabular}{|c|c|c|c|}
\hline $\begin{array}{l}\text { Immunosuppressive } \\
\text { therapy }\end{array}$ & Study & Risk of malignancy & References \\
\hline \multirow[t]{4}{*}{ Azathioprine } & 1 & $\begin{array}{l}162 \text { patients with renal allografts treated with AZA (100 to } 150 \mathrm{mg} / \text { day) found } 22 \text { NMSC developed at } \\
\text { 3-year follow-up }\end{array}$ & [12] \\
\hline & 2 & $\begin{array}{l}\text { A comparison of AZA-based therapy }(n=3,139) \text { and CSA-based therapy }(n=412) \text { in transplant } \\
\text { recipients found } 1,255 \text { skin malignancies developed in the AZA group }(40 \%) \text { compared to } 90 \text { in the } \\
\text { CSA-based group }(22 \%)\end{array}$ & [13] \\
\hline & 3 & $\begin{array}{l}12 \text { malignancies, most commonly NMSC, developed in a group of transplant recipients of } n=287 \\
\text { during 12-month follow-up }\end{array}$ & [14] \\
\hline & 4 & $\begin{array}{l}19 \text { NMSC developed in } 7 \text { out of } 51 \text { kidney recipients }(14 \%) \text { treated with AZA + prednisone for between } \\
4 \text { and } 45 \text { months of treatment; dosing of AZA was kept at approximately } 3 \mathrm{mg} / \mathrm{kg} / \text { day for the duration } \\
\text { after transplantation; } 16 \mathrm{SCC}, 1 \mathrm{BCC} \text { and } 3 \text { keratoacanthomas; conclusions suggested that tumours were } \\
\text { increased in incidence and also prone to early reoccurrence }\end{array}$ & {$[15]$} \\
\hline $\begin{array}{l}\text { Mycophenolate } \\
\text { mofetil }\end{array}$ & 1 & $\begin{array}{l}503 \text { patients with renal allografts were randomised into } 3 \text { groups, } 2 \text { with varied MMF dosages }(2 \mathrm{~g} \text {, } \\
n=173 ; 3 \mathrm{~g}, n=164) \text { and a group with AZA therapy }(n=166) ; 12 \text { malignancies (lymphoma/LPD and } \\
\text { non-skin carcinoma) were found in the group treated with } 3 \mathrm{~g} \text { MMF compared to } 8 \text { treated with } 2 \mathrm{~g} \\
\text { MMF at 3-year follow-up }\end{array}$ & [12] \\
\hline \multirow[t]{3}{*}{ Cyclosporine } & 1 & $\begin{array}{l}142 \text { malignancies developed in } 141 \text { organ transplant recipients treated with cyclosporine, } 41 \% \\
\text { lymphomas compared to } 12 \% \text { observed in the AZA, prednisone or prednisolone group at } 20 \text {-year } \\
\text { follow-up }\end{array}$ & [16] \\
\hline & 2 & $\begin{array}{l}84 \text { malignancies observed in } 1,113 \text { patients treated with combination CSA therapy (group } 1 \text { ) found a } \\
1.99 \% \text { cumulative risk of cancer } 2 \text { years post-transplant versus only } 0.31 \% \text { in the control (patients } \\
\text { without CSA exposure or group 2); } 43 \% \text { of tumours observed ( } n=38 \text { ) were NMSC in group } 1 \\
\text { compared to } 27 \% \text { in group not exposed to CSA, despite shorter time of exposure }\end{array}$ & [17] \\
\hline & 3 & $\begin{array}{l}295 \text { renal allograft recipients treated with AZA + prednisone (115) or AZA + prednisone + CSA (180) } \\
\text { found } 51 \text { patients (19\%) had at least } 1 \text { NMSC; it was found that the incidence of NMSC in AZA + } \\
\text { prednisone was } 29 \text { per 1,000 person-years compared to } 48 \text { per 1,000 years in the group with additional } \\
\text { CSA therapy }\end{array}$ & [18-21] \\
\hline
\end{tabular}

found that the risk of NSMC and lip malignancies was disproportionate between the transplant group on systemic IS and the general population, regardless of whether sun-exposed or not (100- and 50-fold increase, respectively) [41].

\section{Autoimmune diseases}

Studies examining IS therapy in patients with RA are more directly comparable to studies of patients with IED. Patients with rheumatic diseases are commonly treated with similar immune-modulating agents as are patients with IED, including MTX, MMF, CSP and AZA [7,28].

This literature search revealed that a trend away from the use of alkylating agents (cyclophosphamide and chlorambucil) to anti-metabolites and T-cell inhibitors was initiated by findings of the effectiveness of these therapies and concerns regarding the risk of carcinogenesis resulting from an alkylating agent in the treatment of autoimmune diseases [22,42]. Kinlen found that 643 patients with RA treated with AZA and cyclophosphamide had a 13-fold increase of non-Hodgkin lymphoma (NHL) compared to the general population [25].
A number of studies suggested that RA itself increases the risk of malignancy regardless of therapy [43,44]. A large study of 46,000 patients illustrated a 2.7 -fold increased risk of malignancy in patients with RA without IS therapy [45]. This study found a twofold higher incidence of leukaemia, lymphoma, NHL and myeloma in patients with RA compared to the Finnish cancer registry. However, patients with RA on IS therapy demonstrated a significantly greater increase (often documented up to 10to 15 -fold increase) in malignancy than in the study by Isomaki and associates [45]. Baltus and associates, for example, found a fourfold increase in malignancies compared to age-matched controls with RA, not on alkylating agent therapy [22].

A cohort study examining the risk of malignancies in patients with RA treated with MTX indicate that these patients are more susceptible to NHL, melanoma and lung cancer. This long-term follow-up (mean duration 9.3 years) demonstrated a fivefold higher risk of NHL and a threefold increase in melanoma [27]. Similarly, case reports examining the effect of MTX on patients with RA have concluded with similar findings, with some tumours regressing when therapy was withdrawn 
Table 2 Studies which demonstrated an increased incidence of malignancy associated with systemic immunosuppressive therapy in autoimmune diseases

\begin{tabular}{|c|c|c|c|}
\hline $\begin{array}{l}\text { Immunosuppressive } \\
\text { therapy }\end{array}$ & Study & Risk of malignancy & References \\
\hline \multirow[t]{3}{*}{ Cyclophosphamide } & 1 & $\begin{array}{l}461 \text { patients with RA treated with CYP found } 5 \text { bladder cancers developed during } 5 \text {-year follow-up } \\
\text { compared to the expected incidence for the general UK population (0.38) }\end{array}$ & [22] \\
\hline & 2 & $\begin{array}{l}15 \text { malignancies developed in } 81 \text { RA patients treated with CYP with a fourfold increase in the expected } \\
\text { risk of malignancy compared to matched control RA patients not on cytotoxic therapy }\end{array}$ & {$[23]$} \\
\hline & 3 & $\begin{array}{l}119 \text { patients with RA treated with CYP were compared to } 119 \text { matched controls that found } 37 \\
\text { malignancies in } 29 \text { patients and } 16 \text { malignancies in } 16 \text { patients in the control }(p<0.05) \text {; the major } \\
\text { differences were in the number of bladder and NMSC observed ( } 6 \text { and } 8 \text {, respectively) in the } \\
\text { CYP-treated group and none in the control }\end{array}$ & [24] \\
\hline \multirow[t]{2}{*}{ Azathioprine } & 1 & $\begin{array}{l}\text { Analysis of data from } 643 \text { patients with RA found a 13-fold increase in NHL (whether treated with AZA } \\
\text { or CYP) }\end{array}$ & {$[25,26]$} \\
\hline & 2 & $\begin{array}{l}202 \text { patients with RA treated with AZA compared to } 202 \text { RA patients without found a tenfold increase } \\
\text { in } \mathrm{NHL} \text { in patients treated with AZA and a fivefold increase in RA patients without therapy compared } \\
\text { to the general population approximately } 12 \text {-year follow-up }\end{array}$ & \\
\hline Methotrexate & 1 & $\begin{array}{l}458 \text { RA patients treated with MTX found a fivefold increase in NHL and threefold increase in melanoma } \\
\text { compared to the general population with age standardisation; however, risk was increased with prior } \\
\text { CYP exposure prior to MTX ( } 2.5 \text {-fold increase) }\end{array}$ & {$[27]$} \\
\hline Cyclosporine & 1 & $\begin{array}{l}\text { In } 1,252 \text { patients with psoriasis followed up for } 5 \text { years, it was found that } 47 \text { patients (3.8\%) developed } \\
\text { malignancies; the standardised incidence ratio was } 2.1 \text { as compared with the general population; the } \\
\text { study found a sixfold higher incidence in skin malignancies }\end{array}$ & {$[28]$} \\
\hline \multirow[t]{2}{*}{ Biologics } & 1 & $\begin{array}{l}\text { A RCT of } 619 \text { patients with RA treated with adalimumab and with previous MTX exposure found } 4 \\
\text { adalimumab-treated patients developed NMSC, } 1 \text { non-Hodgkin's lymphoma and } 1 \text { adenocarcinoma }\end{array}$ & [29] \\
\hline & 2 & $\begin{array}{l}\text { In a JIA cohort of } 7,812 \text { treated with TNF inhibitors, an increased risk of malignancy in JIA patients } \\
\text { compared to children without JIA was found; however, any increased risk of malignancy in patients } \\
\text { treated with TNF inhibitors was not found }\end{array}$ & {$[30]$} \\
\hline \multicolumn{3}{|c|}{$\begin{array}{l}\text { An epidemiologic study of non-transplant patients treated with systemic immunosuppression treated for greater than } 3 \text { months with } \\
\text { AZA, CYP or chlorambucil found an increase in NHL by } 11-\text { fold, SCC by fivefold and carcinoma of the bladder by fourfold compared to } \\
\text { the general population }\end{array}$} & {$[25]$} \\
\hline
\end{tabular}

[46]. Comparable findings were established by Paul and associates in patients with psoriasis treated with cyclosporine, in whom found was a sixfold higher incidence of skin malignancies, mainly SCC, as compared to the general population [28]. It highlighted that patients treated for greater than 2 years with agents such as MTX, retinoids or another immunosuppressive drug had significantly greater risk than those treated with CSP alone ( $R R=1.8,2.9,2.0$, respectively).

Since the introduction of biologics, such as TNF-alpha inhibitors, there has been considerable debate with regard the risk of malignancy associated with these systemic IS agents. The majority of reliable data is derived from studies of patients with RA participating in RCTs and meta-analyses of such studies $[4,29,47,48]$. A metaanalysis examining adverse effects from infliximab and adalimumab studies found that malignancies were significantly more common in patients when given higher doses of TNF-inhibitors compared to those given low doses [48]. A recent retrospective cohort study by Beukelman and associates investigated 7,812 children with juvenile inflammatory arthritis (JIA) and found that children with this disease had a higher incidence of malignancy, with a standardised incidence ratio

\section{Table 3 Studies which demonstrated an increased incidence of malignancy with systemic immunosuppressive therapy} in IED

\begin{tabular}{l}
\hline Risk of malignancy \\
\hline 8 malignancies were observed in 69 patients with ocular pemphigoid treated with cyclophosphamide and prednisone therapy (2 BCC, \\
2 SCC, 2 leukemias and 1 breast carcinoma) \\
537 patients treated with systemic corticosteroids and/or immunosuppressive therapy found no significant difference between groups \\
treated with immunosuppressive ( $n=330)$ and the control $(n=207), p>0.90$ \\
46 patients treated with systemic immunosuppressive agents for uveitis were examined for malignancy incidence during a 5-year \\
follow-up and compared to patients who only received corticosteroid therapy; 8 malignancies occurred in the experimental group in \\
comparison to 2 in the control $(p<0.05)$
\end{tabular}


(SIR) of 4.4. In contrast to other research, it found that children treated with TNF inhibitors were not at a significantly increased risk of malignancy $(\mathrm{SIR}=0)$ [30].

\section{Inflammatory eye disease}

There is limited data regarding the long-term sequelae of systemic IS therapy in the setting of IED. Murray and associates demonstrated that there was an increased risk of malignancy in patients treated with systemic IS $(n=46)$ therapy in comparison to corticosteroid therapy alone $(n=31)$. In this study, patients treated with corticosteroids were used as a control group as there is no known increased risk of malignancy associated with this drug [33]. The results demonstrated that eight malignancies occurred in the IS group of patients in comparison to two in the corticosteroid treated group $(p<0.05)$. Of particular note, the study established that the type of malignancies observed, namely, NHL, skin and cervical cancers, were similar to neoplasms that developed in patients treated with systemic IS therapy for allografts recipients and other autoimmune diseases. Lane et al. in, a larger study $(n=537)$, concluded that there was not a significantly increased risk of malignancy in patients with IED treated with IS therapy compared to patients treated with corticosteroid alone $(p>0.90)$ [32].

A large retrospective cohort study which examined cancer mortality risk in patients with IED treated with IS therapy found no increased risk of malignancy. Kempen and associates examined the overall mortality of patients with IED treated with systemic IS therapy. This study examined patients treated at five tertiary ocular inflammatory centres between 1979 and 2005 $(n=7957)$ and evaluated the overall mortality by identifiers on US National Death Index [49]. The conclusion drawn from this study indicated that patients with IED who were treated with systemic IS were not at an increased risk of death from malignancy. However, the study did suggest that TNF inhibitors doubled a patient's risk of malignancy. Crucially, the study did not address the prevalence of non-fatal malignancies in this cohort.

\section{Discussion}

There is irrefutable evidence derived from studies of transplant recipients and patients with autoimmune diseases that IS therapy is associated with increased malignancy risk. The limited evidence of malignancy associated with systemic immunosuppressive therapy in patients with IED highlights that this clinical issue has not yet been appropriately addressed.

Data derived from transplant registries have strongly established the potential risk of malignancy that results from prolonged IS therapy in order to preserve graft function $[39,50,51]$. The ability to ascertain whether certain IS drugs are associated with a higher malignancy potential is also influenced by previous patient exposure to other IS therapies. These drugs are typically used in combination or consecutively as the introduction of newer IS agents, such as calcineurin inhibitors and biologics, became more widely used [34]. Long-term followup studies of transplant recipients revealed that neoplasms appeared on average 5 years after transplantation and the commencement of IS therapy $[1,41]$. Immunosuppressive therapy for allograft recipients differs significantly in regards to dosing and cumulative exposure when compared to patients treated for systemic inflammatory diseases. Similarly, the systemic inflammatory state induced by the allograft may drive carcinogenesis, exacerbated by the use of IS therapy [3]. Therefore, it would be naive to affirm the same risk of developing neoplasia without considering that there may be marked differences in risk between different groups of patients.

The literature on the risk carcinogenesis in patients with RA and other inflammatory diseases treated with IS drugs is divided. Numerous studies indicate an increased risk of malignancy with IS therapy, whilst other studies suggest that the increased risk is due to the disease itself (e.g. rheumatoid arthritis [7], psoriasis [28] and Sjögren's disease [52]). Isomaki et al. suggested that the baseline risk of malignancy in patients with RA might be due to chronic activation of the immune system, leading to an increased incidence of lymphoproliferative disorders. The majority of studies indicate that patients with either rheumatoid arthritis or psoriasis are at an increased risk of neoplasia; however, patients treated with systemic IS therapy have a significantly greater incidence of tumours [53-55]. A number of authors have factored in the baseline risk of neoplasia in patients and compared patients on IS therapy for RA and patients not on such therapy [56]. Other studies did not account for this baseline risk of malignancy in RA, which may inflate their malignancy incidence findings [57].

A well-designed study which accurately addresses the concern that systemic IS therapy in IED may predispose to malignancy has not been conducted, and there is limited literature specific to the long-term use of IS therapy in patients with IED. Studies that have examined this important issue have a number of significant shortcomings. The study conducted by Murray et al. established that there was an increased risk of malignancy; however, the findings are affected by a number of important factors. These include a small sample size $(n=87)$ and failure to account for pre-exposure risk of malignancy and not addressing IED with systemic disease associations in the analysis of the results [33]. The limited patient sample size resulted in insufficient statistical power for valid conclusions to be drawn. Lane and associates did not find an increased risk of malignancy in patients treated 
with IS agents, but it is possible that these results were affected by the relatively short-term follow-up period (mean 1.34 years). It is evident that long-term follow up (often $>5$ years) is necessary in studies of patients exposed to IS therapy in order to provide a more accurate clinical picture $[1,58]$. Kempen et al. suggested that systemic IS therapy does not increase the risk of cancer mortality in patients with IED [49]. The study, however, did not address the incidence of non-fatal neoplasia in patients treated with systemic IS therapy for IED. The type of malignancy, grade or histopathology for tumours was not obtained because the primary outcome of this study was defined as the cause of death on certificates identified on the US Death Index. Studies suggest that patients who develop malignancies associated with systemic IS therapy have tumours such as NMSC or lymphomas, which are treatable and may not directly increase mortality; however, they may have a significant impact on morbidity and the patient's quality of life [7,48,54]. Another important issue for ophthalmologists is the need for a regular, focussed and complete physical examination to ensure that the sites of common immunosuppressionrelated malignancies, such as skin, lymph nodes and cervix, are examined. This by necessity requires a careful systemic review and the assistance of other physicians, which may not be readily available in busy eye clinics.

More recently developed therapeutic agents, which are increasingly utilised in the treatment of ocular inflammation, target the activity of inflammatory cells and cytokine signalling. Limited long-term data exists on whether the use of these agents alters the body's ability to detect defective or pre-cancerous cells [59]. Data with regards the safety of biologics (e.g. TNF- $\alpha$ inhibitors) in the treatment of patients with IED are limited due to the recent use of these agents in this setting and a lack of long-term follow-up studies. A number of studies have highlighted the possibility of increased risk of malignancy although none of these studies involved a large patient sample with an appropriate long-term follow-up [60,61]. Similarly, issues related to pre-exposure to MTX and other systemic IS therapy may act as confounders on data reliability.

\section{Recommendations for future studies}

In order to properly address the question of whether the risk of malignancy increases in patients with IED treated with systemic IS therapy, a large collaborative multicentre prospective cohort study with a long-term followup and regular careful systemic evaluation is required. The study design needs to incorporate methodology that addresses possible synergistic factors in carcinogenesis. Examples of such factors include past history and family history of malignancy, smoking status and occupation. In particular reference to NMSC, data on lifetime sun exposure and complexion should be obtained as in the study of Glover et al. [62]. This would evaluate whether an increase in malignancy in IED patients on systemic IS therapy is due predominantly to the immunosuppression or requires the addition of other factors and thus an indirect causation. Furthermore, comparison of patients with similar IED diseases treated with corticosteroid monotherapy as controls, compared to those treated with systemic IS therapy, would address issues with regard to the baseline malignancy risk in patients with IED. It could be argued that patients who are treated with systemic IS therapy may have more severe disease and thus are at significantly greater risk of carcinogenesis. Whilst this is true in the setting of autoimmune disease and transplant recipients, this same conclusion has not been demonstrated in patients with idiopathic IED.

An investigation of the malignancy risk associated with specific IED entities would provide crucial information. A number of tertiary IED centres would be required to achieve this aim by examination of a sufficiently large number of patients. Another important aspect of establishing the carcinogenesis potential of systemic IS therapy in patients with IED is to evaluate any dose-response relationship, which has not been conducted in patients with IED. This will ascertain whether higher dose IS therapy correlates with an increased risk of malignancy in patients with IED.

The large variety of systemic diseases associated with IED (e.g. Behçet's disease, sarcoidosis, Vogt-Kayangi -Harada disease, etc.) poses a problem in an investigation into malignancy risk. Patients with an associated systemic disease may have a significantly increased risk of malignancy compared to those with IED without an underlying disease. A large study, examining the common diseases associated with uveitis (with sufficient statistical power), is necessary to address this issue. Previous studies have tried to identify whether Behçet's disease is associated with an increased risk of malignant disease, but the available literature, consisting mainly of case reports, suggests no significant association $[63,64]$. An investigation into the baseline risk of neoplasia in patients with sarcoidosis also does not support such a correlation [65]. The baseline risk of malignancy has not been established for patients with IED, with or without systemic manifestations.

\section{Prevention}

A crucial aspect of the issue of the relationship between systemic IS therapy and cancer risk is how this can be minimised or prevented. Until it is proven beyond reasonable doubt that patients with IED treated with IS therapy are not at an increased risk of malignancy, it would seem prudent to adopt strategies to minimise such risk. Our suggestions for such an approach are outlined in Table 4 . 
Table 4 Strategy to reduce risk of systemic immunosuppressive therapy related malignancies

\begin{tabular}{ll}
\hline & Strategy \\
\hline Pre-treatment & $\begin{array}{l}\text { Careful pre-treatment evaluation of patients for presence of immunodeficiency (e.g. HIV), past or family history of malignancy and } \\
\text { pre-malignant conditions (e.g. Bowen's disease, CIN of cervix, GIT polyps, leukoplakia of lip) }\end{array}$ \\
$\begin{array}{l}\text { Dosages and } \\
\text { therapy }\end{array}$ & $\begin{array}{l}\text { Minimise dose and duration of immunosuppressive therapy (e.g. use of alkylating agents, such as cyclophosphamide for < 12 } \\
\text { months) - consider drugs with less oncogenic potential (e.g. MTX, mTOR inhibitors (sirolimus)) }\end{array}$ \\
Education & $\begin{array}{l}\text { Patient education - stop smoking, avoid excessive exposure to UV radiation, immunisation against HPV, regular self-examination } \\
\text { (e.g. skin, lips, breast) }\end{array}$ \\
Follow-up & $\begin{array}{l}\text { Regular and annual review - screening for common immunosuppressive therapy associated malignancies (e.g. skin, cervix, } \\
\text { bladder, lymph nodes) }\end{array}$ \\
\hline
\end{tabular}

These are based in part on recommendations from the Kidney Disease: Improving Global Health Outcomes group. In relation to skin and lip cancers, it is recommended that patients should be educated about the risk of skin cancer, especially in subjects with a history of high levels of sun exposure and who are fair-skinned and/or have a history of previous NMSC [37]. All patients should be encouraged to practice regular self-examination and have annual skin and lip examinations by health professionals. Recommendations for non-skin cancer-related malignancies are the same as for cancer screening of the general population, with emphasis on cervical, breast, colon, renal and haematological examinations [66]. Immunisation against the human papilloma virus may also help reduce the incidence of cervical cancer in this population. Epidemiological studies of renal transplant patients indicate that the duration and intensity of IS therapy influence the incidence of post-transplant malignancies. Thus, modulation of IS therapy and minimising exposure to drugs known to have a high association with malignancy, such as cyclophosphamide, should be minimised and consideration given to the use of less oncogenic therapy, such as methotrexate and mTOR inhibitors, such as sirolimus [67]. There is evidence that mTOR inhibitors have a beneficial effect in terms of cancer regression in patients with post-transplant malignancy, and this will need to be confirmed in long-term studies.

\section{Conclusion}

The benefits of treatment of IED with IS drugs must be weighed against possible complications associated with such therapy [41]. The vision-saving benefits of the use of antimetabolites, calcineurin inhibitors and biologicals are thought to outweigh the risks [27]. A well-designed, comprehensive, multi-centre long-term follow-up study is required to evaluate the risk of malignancy in patients with specific IED diseases treated with defined systemic IS therapy. Such a study could provide valuable information that would influence the evaluation, investigation, prevention strategies, routine follow-up and screening of individuals. For example, patients at increased risk of malignancy, especially skin cancers, should receive advice regarding UV exposure and have regular skin examination. Immunisation against human papilloma virus could reduce the prevalence of cervical cancer. Similarly, long-term surveillance of patients treated with systemic IS therapy for IED should include regular systemic examination looking specifically for evidence of malignancy (skin, cervix, lymph nodes and blood). Until it has been ascertained as to whether or not there is an increased risk of malignancy associated with systemic IS therapy in patients with severe IED, increased vigilance is required to ensure that patients are regularly reviewed, appropriately and systematically examined, investigated and have long-term follow-up to detect and treat malignancies as early as possible.

\section{Competing interests}

The authors report no proprietary or commercial interest in any product mentioned or concept discussed in this article. The authors declare that they have no competing interests.

\section{Authors' contributions}

WBY conducted the initial literature search, wrote the initial draft and contributed critical appraisal. DW conceived the original idea for the review, provided direction for the manuscript and original ideas regarding prevention strategies. PMC provided original contributions to the discussion as well as providing direction and ideas regarding the literature in the field of inflammatory eye disease. The manuscript was a collaborative effort with all authors involved in the drafting and editing process. All authors read and approved the final manuscript.

\section{Acknowledgements}

The authors would like to acknowledge the University of New South Wales, School of Medical Sciences and the Save Sight Institute, the University of Sydney.

\section{Author details}

'Inflammation Research Unit, School of Medical Sciences, University of New South Wales, Sydney, NSW 2052, Australia. Department of Ophthalmology, St Vincent's Hospital, Sydney, NSW 2052, Australia. ${ }^{3}$ Save Sight Institute, Sydney University, Sydney, NSW 2001, Australia. ${ }^{4}$ Ocular Inflammation Research Group, School of Medical Sciences, University of New South Wales, Sydney, NSW 2052. 'Lowy Cancer Research Centre, Faculty of Medicine, 
University of New South Wales, Room 516, Level 5, Sydney, NSW 2052, Australia.

\section{Received: 22 March 2013 Accepted: 15 May 2013} Published: 31 May 2013

\section{References}

1. Penn I (2000) Post-transplant malignancy: the role of immunosuppression. Drug Saf 23:101-113

2. Euvrard S, Kanitakis J, Claudy A (2003) Skin cancers after organ transplantation. N Engl J Med 348:1681-1691

3. Watorek EBM, Smolska D, Patrzalek D, Klinger M (2011) Malignancy after renal transplantation in the new era of immunosuppression. Ann Transplant 16:14-18

4. Kiely B, O'Flaherty J, Surah S, Kieran J, O'Donnell D, Bergin C, Mulcahy F (2010) HIV-related malignancies pre- and post-highly active antiretroviral therapy: experiences in an inner city tertiary referral centre. Int J STD AIDS 21:332-336

5. Reekie J, Kosa C, Engsig F, Monforte A, Wiercinska-Drapalo A, Domingo P, Antunes F, Clumeck N, Kirk O, Lundgren JD, Mocroft A (2010) Relationship between current level of immunodeficiency and non-acquired immunodeficiency syndrome-defining malignancies. Cancer 116:5306-5315

6. Ippoliti G, Rinaldi M, Pellegrini C, Vigan M (2005) Incidence of cancer after immunosuppressive treatment for heart transplantation. Crit Rev Oncol Hematol 56:101-113

7. Krathen M, Gottlieb A, Mease P (2010) Pharmacologic immunomodulation and cutaneous malignancy in rheumatoid arthritis, psoriasis, and psoriatic arthritis. J Rheumatol 37:2205-2215

8. McCluskey PJ, Towle HM, Lightman S (2000) Management of chronic uveitis. BMJ 320:555-558

9. Foster S (1986) Cicatricial pemphigoid. Trans Am Ophthalmol Soc 84:527-663

10. Abdalla MI, Bahgat N (1973) Long-lasting remission of Behcet's disease after chlorambucil therapy. BJO 57:706-711

11. Foster S (1980) Immunosuppressive therapy for external ocular inflammatory disease. Ophthalmology 87:140-150

12. Mathew TH, Tricontinental Mycophenolate Mofetil Renal Transplantation Study Group (1998) A blinded, long-term, randomized multicenter study of mycophenolate mofetil in cadaveric renal transplantation: results at three years. Transplantation 65:1450-1454

13. Penn I (1996) Cancers in cyclosporine-treated vs azathioprine-treated patients. Transplant Proc 28:876-878

14. Wiesner R, Rabkin J, Klintmalm G, McDiarmid S, Langnas A, Punch J, McMaster P, Kalayoglu M, Levy G, Freeman R, Bismuth H, Neuhaus P, Mamelok R, Wang W (2001) A randomized double-blind comparative study of mycophenolate mofetil and azathioprine in combination with cyclosporine and corticosteroids in primary liver transplant recipients. Liver Transpl 7:442-450

15. Walder B, Robertson M, Jeremy D (1971) Skin cancer and immunosuppression. Lancet 298:1282-1283

16. Penn I (1987) Cancers following cyclosporine therapy. Transplantation 43:32-35

17. Hiesse C, Rieu P, Kriaa F, Larue JR, Goupy C, Neyrat N, Charpentier B (1997) Malignancy after renal transplantation: analysis of incidence and risk factors in 1700 patients followed during a 25-year period. Transplant Proc 29:831-833

18. Kinlen L, Sheil A, Peto J, Doll R (1979) Collaborative United KingdomAustralasian study of cancer in patients treated with immunosuppressive drugs. BMJ 2:1461-1466

19. Penn I (1981) The price of immunotherapy. Curr Probl Surg 18:681-751

20. Penn I (1986) Cancer is a complication of severe immunosuppression. Surg Gynecol Obstet 162:603-610

21. Penn I (1987) Neoplastic consequences of transplantation and chemotherapy. Cancer detection and prevention Supplement: official publication of the International Society for Preventive Oncology, Inc 1:149-157

22. Baltus J, Boersma J, Hartman A, Vandenbroucke J (1983) The occurrence of malignancies in patients with rheumatoid arthritis treated with cyclophosphamide: a controlled retrospective follow-up. Ann Rheum Dis 42:368-373
23. Radis CD, Kahl LE, Baker GL, Wasko MC, Cash JM, Gallatin A, Stolzer BL, Agarwal AK, Medsger TA Jr, Kwoh CK (1995) Effects of cyclophosphamide on the development of malignancy and on long-term survival of patients with rheumatoid arthritis. A 20-year followup study. Arthritis Rheum 38:1120-1127

24. Baker G, Kahl L, Zee B, Stolzer B, Agarwal A, Medsger T Jr (1987) Malignancy following treatment of rheumatoid arthritis with cyclophosphamide: longterm case-control follow-up study. Am J Med 83:1-9

25. Kinlen $L$ (1985) Incidence of cancer in rheumatoid arthritis and other disorders after immunosuppressive treatment. Am J Med 78:44-49

26. Silman AJ, Petrie J, Hazleman B, Evans SJ (1988) Lymphoproliferative cancer and other malignancy in patients with rheumatoid arthritis treated with azathioprine: a 20 year follow up study. Ann Rheum Dis 47:988-992

27. Buchbinder R, Barber M, Heuzenroeder L, Wluka A, Giles G, Hall S, Harkness A, Lewis D, Littlejohn G, Miller MH, Ryan PF, Jolley D (2008) Incidence of melanoma and other malignancies among rheumatoid arthritis patients treated with methotrexate. Arthritis Care Res 59:794-799

28. Paul CF, Ho VC, McGeown C, Christophers E, Schmidtmann B, Guillaume JC, Lamarque V, Dubertret $L$ (2003) Risk of malignancies in psoriasis patients treated with cyclosporine: a 5 y cohort study. J Investig Dermatol 120:211-216

29. Keystone E, Kavanaugh A, Sharp J, Tannenbaum H, Hua Y, Teoh L, Fischkoff SA, Chartash EK (2004) Radiographic, clinical, and functional outcomes of treatment with adalimumab (a human anti-tumor necrosis factor monoclonal antibody) in patients with active rheumatoid arthritis receiving concomitant methotrexate therapy: a randomized, placebo-controlled, 52-week trial. Arthritis Rheum 50:1400-1411

30. Beukelman T, Haynes K, Curtis J, Xie F, Chen L, Bemrich-Stolz C, Delzell E, Saag KG, Solomon DH, Lewis JD (2012) Rates of malignancy associated with juvenile idiopathic arthritis and its treatment. Arthritis Rheum 64:1263-1271

31. Thorne JE, Woreta FA, Jabs DA, Anhalt GJ (2008) Treatment of ocular mucous membrane pemphigoid with immunosuppressive drug therapy. Ophthalmology 115:2146-2152, e1

32. Lane L, Tamesis R, Rodriguez A, Christen W, Akova Y, Messmer E, PedrozaSeres M, Barney N, Foster CS (1995) Systemic immunosuppressive therapy and the occurrence of malignancy in patients with ocular inflammatory disease. Ophthalmology 102:1530-1535

33. Murray NL, McCluskey PJ, Wakefield D (1994) Increased risk of malignancy in patients with uveitis treated with systemic immunosuppressive therapy. Elsevier, New York, pp 421-424

34. Kauffman M, Cherikh W, McBride M, Cheng Y, Hanto D (2006) Posttransplant de novo malignancies in renal transplant recipients: the past and present. Transpl Int 19:607-620

35. Penn I, Brunson ME (1988) Cancers after cyclosporine therapy. Transplant Proc 20:885-892

36. Hartevelt M, Bavinck J, Kootte A, Vermeer B, Vandenbroucke J (1990) Incidence of skin cancer after renal transplantation in The Netherlands. Transplantation 49:506-509

37. Rama I, Grinyo JM (2010) Malignancy after renal transplantation: the role of immunosuppression. Nat Rev Nephrol 6:511-519

38. Kelly G, Meikle W, Moore D (1989) Enhancement of UV-induced skin carcinogenesis by azathioprine: role of photochemical sensitisation. Photochem Photobiol 49:59-65

39. Bavinck J, Hardie D, Green A, Cutmore S, MacNaught A, O'Sullivan B, Siskind V, Van Der Woude FJ, Hardie IR (1996) The risk of skin cancer in renal transplant recipients in Queensland. Australia. A follow-up study. Transplantation 61(5):715-21

40. McGregor JM, Berkhout RJM, Rozycka M, Schegget J, Bouwes Bavinck JN, Brooks L, Crook T (1997) p53 mutations implicate sunlight in post-transplant skin cancer irrespective of human papillomarivus status. Oncogene 15:1737-1740

41. Lindelöf B, Sigurgeirsson B, Gäbel H, Stern RS (2000) Incidence of skin cancer in 5356 patients following organ transplantation. Br J Dermatol 143:513-519

42. Asten P, Barrett J, Symmons D (1999) Risk of developing certain malignancies is related to duration of immunosuppressive drug exposure in patients with rheumatic diseases. J Rheumatol 26:1705-1714

43. Mellemkjær L, Linet MS, Gridley G, Frisch M, Møller H, Olsen JH (1996) Rheumatoid arthritis and cancer risk. Eur J Cancer 32:1753-1757

44. Turesson C, Matteson EL (2013) Malignancy as a comorbidity in rheumatic diseases. Rheumatology (Oxford) 52(1):5-14 
45. Isomaki H, Hakulinen T, Joutsenlahti U (1978) Excess risk of lymphomas, leukemia and myeloma in patients with rheumatoid arthritis. J Chronic Dis 31:691-696

46. Beauparlant P, Papp K, Haraoui B (1999) The incidence of cancer associated with the treatmentof rheumatoid arthritis. Semin Arthritis Rheum 29:148-158

47. van de Putte LBA, Atkins C, Malaise M, Sany J, Russell AS, van Riel PLCM, Settas L, Bij|sma J, Todesco S, Dougados M, Nash P, Emery P, Walter N, Kaul M, Fischkoff S, Kupper H (2004) Efficacy and safety of adalimumab as monotherapy in patients with rheumatoid arthritis for whom previous disease modifying antirheumatic drug treatment has failed. Ann Rheum Dis 63:508-516

48. Bongartz T, Sutton A, Sweeting M, Buchan I, Matteson E, Montori V (2006) Anti-TNF antibody therapy in rheumatoid arthritis and the risk of serious infections and malignancies. JAMA 295:2275-2285

49. Kempen J, Ebenezer D, Dun J, Foster P, Gangaputra P, Hanish A, Helzlsouer KJ, Jabs DA, Kaçmaz RO, Levy-Clarke GA, Liesegang TL, Newcomb CW, Nussenblatt RB, Pujari SS, Rosenbaum JT, Suhler EB, Thorne JE (2009) Overall and cancer related mortality among patients with ocular inflammation treated with immunosuppressive drugs: retrospective cohort study. BMJ 339:b2480

50. Pham SM, Kormos RL, Landreneau RJ, Kawai A, Gonzalez-Cancel I, Hardesty RL, Hattler BG, Griffith BP (1995) Solid tumors after heart transplantation: lethality of lung cancer. Ann Thorac Surg 60:1623-1626

51. Crespo-Leiro M, Villa-Arranz A, Manito-Lorite N, Paniagua-Martin M, Rábago G, Almenar-Bonet L, Alonso-Pulpón L, Mirabet-Pérez S, Diaz-Molina B, González-Vilchez F, Arizón de Prado JM, Romero-Rodriguez N, DelgadoJimenez J, Roig E, Blasco-Peiró T, Pascual-Figal D, De la Fuente GL, Muñiz J (2011) Lung cancer after heart transplantation: results from a large multicenter registry. Am J Transplant 11:1035-1040

52. Masaki Y, Sugai S (2004) Lymphoproliferative disorders in Sjogren's syndrome. Autoimmun Rev 3:175-182

53. Hogan D, To T, Gran L, Wong D, Lane P (1989) Risk factors for basal cell carcinoma. Int J Dermatol 28:591-594

54. Jones M, Symmons D, Finn J, Wolfe F (1996) Does exposure to immunosuppresive therapy increase the 10 year maligancy and mortality risks in rheumatoid arthritis? A matched cohort study. Rheumatology (Oxford) 35:738-745

55. Flytström I, Stenberg B, Svensson Å, Bergbrant IM (2008) Methotrexate vs. cyclosporin in psoriasis: effectiveness, quality of life and safety. A randomized controlled trial. $\mathrm{Br}$ J Dermatol 158:116-121

56. Burmester G, Mease P, Dijkmans B, Gordon K, Lovell D, Panaccione R, Perez J, Pangan AL (2009) Adalimumab safety and mortality rates from global clinical trials of six immune-mediated inflammatory diseases. Ann Rheum Dis 68:1863-1869

57. Buchbinder R, Forbes A, Hall S, Dennett X, Giles G (2001) Incidence of malignant disease in biopsy-proven inflammatory myopathy. A populationbased cohort study. Ann Intern Med 134:1087-1095

58. Jensen P, Hansen S, Møller B, Leivestad T, Pfeffer P, Geiran O, Fauchald P, Simonsen S (1999) Skin cancer in kidney and heart transplant recipients and different long-term immunosuppressive therapy regimens. J Am Acad Dermatol 40:177-186

59. Myra L, Sloper C, Powell RJ, Dusa HS (1999) Tacrolimus (FK506) in the treatment of posterior uveitis refractory to cyclosporine. Ophthalmology 106:723-728

60. Suhler EB, Smith JR, Wertheim MS, Lauer AK, Kurz DE, Pickard TD, Rosenbaum JT (2005) A prospective trial of infliximab therapy for refractory uveitis: preliminary safety and efficacy outcomes. Arch Ophthalmol 123:903-912

61. Imrie F, Dick A (2007) Biologics in the treatment of uveitis. Curr Opin Ophthalmol 18:481-486

62. Glover MT, Deeks JJ, Raftery MJ, Cunningham J, Leigh IM (1997) Immunosuppression and risk of non-melanoma skin cancer in renal transplant recipients. Lancet 349:398

63. Houston K, O'Duffy J, McDuffie F (1978) Behcet's disease associated with a lymphoproliferative disorder, mixed cryoglobulinemia, and an immune complex mediated vasculitis. J Rheumatol 5:217-223

64. Cengiz M, Altundag M, Zorlu A, Güllü I, Özyar E, Atahan I (2001) Malignancy in Behçet's disease: a report of 13 cases and a review of the literature. Clin Rheumatol 20:239-244
65. Seersholm N, Vestbo J, Viskum K (1997) Risk of malignant neoplasms in patients with pulmonary sarcoidosis. Thorax 52:892-894

66. Kidney Disease: Improving Global Outcomes (KDIGO) Transplant Work Group (2009) KDIGO clinical practice quideline for the care of kidney transplant recipients. Am J Transplant 9(Suppl 3):S1-S155

67. Euvrard S, Morelon E, Rostaing L, Goffin E, Brocard A, Tromme I, Broeders N, del marmol V, Chatelet V, Dompmartin A, Kessler M, Serra AL, Hofbauer GFL, Pouteil-Noble C, Campistol JM, Kanitakis J, Roux AS, Decullier E, Dantal J (2012) Sirolimus and secondary skin-cancer prevention in kidney transplantation. N Engl J Med 367:329-339

doi:10.1186/1869-5760-3-48

Cite this article as: Yates et al:: Are patients with inflammatory eye disease treated with systemic immunosuppressive therapy at increased risk of malignancy?. Journal of Ophthalmic Inflammation and Infection 2013 3:48.

\section{Submit your manuscript to a SpringerOpen ${ }^{\circ}$ journal and benefit from:}

- Convenient online submission

- Rigorous peer review

- Immediate publication on acceptance

- Open access: articles freely available online

- High visibility within the field

- Retaining the copyright to your article

Submit your next manuscript at $\gg$ springeropen.com 